\title{
Leadership: A Case Study on the Importance of Ethics and Trust
}

\author{
Eric L. Prentis ${ }^{a}{ }^{*}$, Sunday E. Igoni ${ }^{b}$ \\ a Wenzhou-Kean University, Assistant Professor, College of Business \& Public Management, Wenzhou, China 325060. \\ b Wenzhou-Kean University, Lecturer 2, College of Business \& Public Management, Wenzhou, China 325060. \\ *Corresponding author's email address: eric.prentis@gmail.com
}

\section{A R T I C L E I N F O}

Received: 01-03-2016

Accepted: 14-03-2016

Available online: 01-05-2016

Keywords:

Corruption;

Ethical Leadership;

Nigerian Societal Corruption;

Organizational Behavior;

Trust.

JEL Classification:

E03 ; H10 ; M10.

\section{A B S T R A C T}

This research is important because it empirically tests why ethical behavior by business and government leaders is essential for good management-which is to earn trust from customers and constituents-thus ensuring organizations are successful, for the greater good, over the long term, especially in the global marketplace. Law and morality are two standards by which business and government leaders are judged, but these norms fail whenever laws are not enforced and morality is disregarded. Five research questions on leadership are statistically tested, using a Likert-scale response measure questionnaire-based on "perceptions of societal corruption" and "trust levels," using Bandura's "aggressive behavior modification theory," as the model for analysis. Nigeria is selected as the location of this case study on leadership ethics and trust, because Nigerian government officials have a long history of unethical and corrupt behavior. Descriptive statistics, along with chi-square quantitative research methods reveals "perceptions of societal corruption" in Nigeria are high and "trust levels" for government leaders are very low. Leaders in Nigeria are only as ethical as the code-of-conduct prevalent in their country-where cultural, economic and legal factors contribute to the nation's corrupt society-which may cause Nigeria to become a failed state. To change the Nigerian culture of societal corruption-education is necessary-to instruct elected officials, civil servants, business leaders and Nigerian society, at large, on the importance of ethics and trust. Nigerian government and business leaders should institute an ethics policy - and implement five suggested reforms presented in this paper-which will help establish government leader's ethical integrity and improve citizens' trust and confidence in their government. Recommendations for future research on government and business leadership ethics and trust are offered.

This is an open access article under the terms of the Creative Commons Attribution License 4.0, which allows use, distribution and reproduction in any medium, provided the original work is properly cited.

DOI: http://dx.doi.org/10.18533/job.v1i3.22 ISSN: 2380-4041 (Print), 2380-405X (Online)

\subsection{Introduction}

Ethical business and government leadership-necessary for organizational success, for the greater good, over the long term, especially in the global marketplace-is empirically tested in this research. Long-term success in business and in government requires transparency and trust from managers, customers, employees, vendors and government leaders. Once an individual or organization loses trust, it is almost impossible to regain. Trust is not given; it is earned-by honorable government and business leaders who demonstrate ethical behavior, by being honest and forthright when dealing with their customers and constituents (Kulshreshtha, 2015). 
Business and government leaders, to be effective, require respect from their employees, which entails more than just paying them a good salary. When a business or government organization goes through a major change or reorganization, the integrity of the organization's leaders is paramount. The followers have to trust the leaders, in order to make significant progress on the stated new organizational goals and procedures during the transformation process (Prentis, 1987), which becomes uncertain when the employees do not trust their corporate leaders-for example, during unsuccessful mergers and acquisitions (Sharif and Scandura, 2014).

Potential customers or clients have to trust the managers and employees supplying the good or service, to have integrity of character and adhere to an ethical code-of-conduct. Either that or the business transaction is not begun. Customers are psychologically reluctant to do business with those who are perceived to be dishonest and display criminal behavior (Chughtai et al., 2015). A good reputation is vital to secure ongoing business and for high long-term profitability. Employees rely on the realized values of their mangers to determine how best to conduct themselves when interacting with customers, in a new or difficult situation. Also, once a customer is taken advantage of by a business, the company has lost that wronged customer, for good.

Law and morality are two standards by which government and business leaders are judged. To be effective, law enforcement should punish leaders who are caught disobeying the law. Morality has consequences as well. Immoral acts may prompt individual guilt and group condemnation, while moral acts may result in virtuous feelings and admiration from the community-at-large (Chan and Mak, 2014). Praise, self-esteem, recognition, and not wanting to be excluded from the societal group are powerful inducements for moral behavior. However, when the law fails to be enforced and morality is disregarded, society is at the mercy of its leaders.

People acquire moral values and a code-of-conduct from a combination of culture, religion, and philosophy. Standards of behavior are the norm, unless a person has a mental illness-for example, displaying antisocial personality disorders (ASPD) (Ferguson, 2010). The best way to engender trust in a business or government organization is for the leaders to possess ethical principles, have integrity and be consistently honest in their dealings with customers or constituents. Not because they are required to do so by law, but because in moral philosophy, it is the proper thing to do, and is therefore, good for business, over the long term.

Trust is important for effective government, which provides the general structure for conducting business. There is a trust-based mechanism that supports the association between ethical leaders and the discretionary behavior of followers (Newman et al., 2014). An ethical government state of affairs is essential, because it promotes business and respect for the people and institutions of the country. Leaders, including elected politicians and business managers, who do not establish procedures to promote ethical conduct are responsible - along with those in the organization who plan, perform, and profit for their offenses (Lussier, 2010).

Leaders in government and in business should be courageous, and demonstrate honest and trustworthy behavior. Perceptions are important. Communication from leaders should reinforce high ideals. Transparency in decision making and actions taken are necessary to develop trust in the country's citizens or employees of the firm. Arbitrary and unexplained business decisions and actions by leaders are counterproductive-because uncertainty prevails-people stop listening, progress stops, and employees revert back to their own agendas (Delhey and Newton, 2003).

Corruption is the opposite of ethical behavior. Therefore, integrity and corruption do not coexist. Werlin (2003) analyses organizational, cultural and structural-functional factors of a country's governance to report on the devastating effect government corruption has on a nation's economy. Countries are either rich or poor-not because of a country's wealth or lack of resources-but because of differences in ethical government leadership. During the 1980s, "kleptocratic" regimes in Nigeria, the Philippines, and in Zaire become well known to the world-because of their leader's massive diversion of state resources away from their people, who lived in poverty. Government corruption, which is immoral and illegal, is contrary to ethical behavior in government leaders, and undermines constituent's trust-making a country poor.

Agba (2010) states, if not for widespread societal corruption, Nigeria would be a financially sound country. Mbaku (2000) describes a consequence of societal corruption in Africa, and particularly in Nigeria, as the reluctance of foreigners to invest in Nigeria, which means that Nigerians are losing out in the global marketplace. The cost of corruption in Nigeria is high, and many foreign companies are not willing to take the risk of losing profits to corrupt government practices. The World Bank's (1994) report maintains, in the early 1990s, that monies - up to two thirds of the national income-mostly from rich oil revenues, are unaccounted for due to overspending, and are presumed stolen by Nigeria's political and business leaders (Jerome et al., 2005). 
Another form of corruption that causes Nigeria's poverty is many large industrial projects, like those of the Ajaokuta Steel Company, which strayed from their goals, yet enriched the few corrupt business leaders and government officials through monetary kickbacks (Ijomah, 2000). When the Ajaokuta project ended in failure, before it was completed, billions of dollars disappeared. Under similar circumstances, other less-high-profile state projects did not receive the same number of headlines as the Ajaokut project, but were subject to the same degree of business and government corruption. Infrastructure as well is subject to corruption. For example, the outcome for electricity production for the security of Nigeria is poor, due to extensive graft and corruption.

Government officials also make use of "ghost workers," as another way of plundering the state treasury. Where government officials include nonexistent workers in the payroll, and keep the "ghost workers"' salaries for themselves (Ayittey, 1992).

Since independence in 1960, Nigeria has passed through about nine coups, in less than 50 years, because of widespread political corruption (Falola, 1999). Nigeria's dire economic problems are a direct result of widespread societal corruption, nepotism, lawlessness and poverty that have led to political instability and death (Daloz, 2005; French, 2004; Games, 2004; Guest, 2004; Werlin, 2003). Corruption is a social condition that leads to starvation of the less privileged in Nigerian society, and a lack of education accompanies the absence of Nigeria's competitive edge with the rest of the world, in the global marketplace, which may lead to Nigeria becoming a failed state.

Nigeria has a long history of unethical government leaders and documented corruption. Therefore, Nigeria is selected as the location of this case study on leadership ethics and trust- to test whether government corruption and the lack of ethical leadership in Nigeria underlies the country's extreme poverty, and failure in the global economy. Additionally, Nigeria can be used as a proxy for other African countries facing similar wide-spread government graft and corruption (Adjibolosoo, 2005).

Benin City, in Edo State, Nigeria, is an ancient city with many cultural traditions. Benin is a metropolitan city with a population of about 1 million people, is located in the center of Nigeria, and attracts business people from all over the country. Benin is selected as the focus of this case study, because Benin is representative of Nigeriamaking this case study rich in content while helping to explain Nigerians' perceptions of corruption within their society (Igoni, 2009).

The theoretical framework of analysis for this case study on leadership is Bandura's (1973) "aggressive behavior modification theory," which explains that behavior can be changed when persons with behavioral problems have an alternative constructive behavioral model available for their acceptance. Bandura's theory is important to this case study because societal corruption is a behavioral problem that should be affirmatively addressed in order to be reformed. Bandura explains that an unwanted behavior can be altered if a continuous approach of modification is used to change the behavior. This case study measures the "perceptions of societal corruption" in Nigeria and the "trust levels" for government leaders, by surveying a random sample of residents from Benin City, Nigeria. Understanding the tested variables investigated in this research will help identify practices to transform the behavior of Nigerians, and may help to bring about positive societal change for Nigeria, and for other countries in Africa facing a similar situation.

The remainder of this paper is organized as follows. Section 2.0 presents the design of the Likert-scale response measure questionnaire used in testing "perceptions of societal corruption" in Nigeria and the "trust levels" for government leaders, how the variables are measured, how the pilot study is conducted to verity the reliability of the questionnaire, and describes how the questionnaires are administered to collect the empirical data. Section 3.0 discusses the significance of the five research questions' chi-square statistical calculations, and the collected descriptive statistical results on answers to questions in the questionnaire. Section 4.0 reaches conclusionsbased on the significant results of this case study-using Bandura's theory for model analysis, when presenting policy reforms to help solve Nigeria's societal and leadership corruption problems. Suggestions for future research on government and business leadership ethics and trust are offered.

\subsection{Data and methodology}

\subsection{Logic of the problem statement}

Studies have shown that no matter who is in power in Nigeria, since independence in 1960, the results have been the same-continued patterns of widespread political corruption (Smith, 2001; French, 2004; Guest, 2004). This case study empirically tests and explains this pattern of corrupt Nigerian leadership behavior. It also helps to determine whether persistent pervasive corruption results in citizens' mistrust in their government 
Statistics is used to measure and analyze the empirical data, for decision making, which agrees with McNabb's (2002) description of content analysis. Statistical outcomes may then be used to educate Nigerians, and all Africans, about the levels of perceived corruption and patterns of mutual trust among the people of Nigeria.

\subsection{Research questions}

Five hypotheses are tested, and the results present a statistical portrait of a survey of respondents on "perceptions of societal corruption" in Nigeria and "trust levels" in government leaders, and in each other. This study is designed to provide information that is of use to government and business policymakers, which will help in decision-making toward positive social change in Nigeria, as well as other African countries facing similar circumstances.

\subsection{Measurement of the variables}

The two key variables of "perceptions of societal corruption" in Nigeria and "trust levels" for government leaders are empirically measured in this study, using descriptive statistics, which is a nonparametric method. The majority of the questions have three-to-four response options, which are tabulated. The higher the number of questionnaire respondents who select one option, the more favorable that choice represents the views of the participants, in comparison to the rest of the options for that question.

The questionnaire is designed to measure the respondents' awareness of "perceptions of societal corruption" in Nigeria and "trust levels" for government leaders, which do not have a linear relationship. Consequently, using percentages to relate to the different options in the questionnaire is a better and more reliable research method than using multiple regressions to analyze the data (Afrobarometer, 2005). The components of "perceptions of societal corruption" measured in this study are bribery, fraud, nepotism, extortion, and embezzlement.

\subsection{Questionnaire design}

This research examines the "perceptions of societal corruption" in Nigeria and "trust levels" for government leaders by surveying a random sample of Nigerian residents from Benin City, about honesty in their government, along with their fellow citizens' levels of mutual trust. The respondents are asked to answer questions on a 26item Likert-scale, self-administered questionnaire (see Appendix)—during a one week period, from Monday through Sunday, in February, 2009. The results are statistically analyzed to gain insight into Nigerian society, with the goal of bringing about positive social change in the country. Descriptive statistics, along with chi-square statistical quantitative methods, offer the best explanation of "perceptions of societal corruption" in Nigeria and "trust levels" for Nigerian government leaders.

The chi-square goodness-of-fit test is used to test the first three research question hypotheses. The last two research question hypotheses are tested using the chi-square test for independence. The analyzed data are gathered with a questionnaire that uses Likert-scaling, with three or more response options. Some of the data are collected at the ordinal level, which are used with the chi-square test of independence, to test the hypotheses generated from the final two research questions. Other questionnaire data are collected at the nominal level; these data are used with the chi-square goodness-of-fit test, to evaluate the hypotheses generated from the first three research questions.

\subsection{Control of contextual factors}

The case study questionnaire is made available at four separate locations, covering a wide area in Benin City, to ensure the diversity of Benin's population is included in the survey. The four areas with heavy pedestrian activity are selected to collect the questionnaire data-so that prospective participants can easily come into contact with the questionnaire administrators. Booths are made available for use by each respondent, while completing the survey questionnaire. Distractions are minimized by the survey administrators' handling of multiple (3 to 5) respondents at a time, in each location. In addition, the questionnaire's syntax is simple; therefore, the respondents clearly understand how to answer the questions. This procedure also prevents the participants from responding more than once to the questionnaire, a situation that would compromise the validity of the study. The participants' experiences are expected to allow them to reflect on their perceptions of societal corruption in Nigeria, and its impact on the Nigerian population.

J. Maxwell (2005) suggests that to understand a specific phenomenon, it is necessary to use the participants' experiences to explain the outcome. In this study, the researchers would have had to be in close contact with the corrupt government officials. Such proximity would be almost impossible in Nigeria, because outsiders would not 
be allowed into the inner circle, where the corrupt activities take place. Therefore, understandably, the use of close-contact corrupt participant experience is not pursued in this research.

The use of a questionnaire makes it possible for the researchers to have more personal contact with the respondents. This process helps to better identify who actually answers the questions at the time of the survey. Owing to this personal contact, the analysis of the data is different from data that could have been collected by telephone. However, the number of people in Nigeria with telephones is difficult to determine. In addition, most Nigerians use cell phones. Therefore, to track the ownership of mobile phones, for survey-based research, is nearly impossible (Guest, 2004).

An intercept sampling method is used to select participants, at each location for this case study, which guarantees a diverse sample of respondents. In addition, all participants are 25 years and older. The rationale for this age requirement is to test only mature adults. Because of the seriousness of this case study, the researchers believe the participants should be able to respond respectfully, and obey the rules of engagement, to produce more accurate survey data.

\subsection{Sample size and statistical significance}

The sample size employed in this case study is 1,000 participants, far greater than the minimal suggested for this type of statistical study (Maxwell, 1961). To ensure a random sample is taken for this case study, four different locations are selected, covering a wide area in Benin City. Anyone who passes through these locations at the time of the survey qualifies to participate. Survey administrators intercepted participants by choosing every third person who passes through each location, which adheres to the tenets of random sampling (Leedy, 1985).

The participants are Muslims, Christians, and those of the African traditional religion. At each of the four locations where the survey is given, one of the administrators is responsible for explaining the purpose of the study to all passersby, who are intercepted. Those who are interested are free to participate, after reading and signing the consent form. No compensation of any kind is given to any of the volunteer participants.

\subsection{Pilot study}

To verify the reliability of the case study questionnaire, to measure "perceptions of societal corruption" in Nigeria and "trust levels" for Nigerian government leaders-a pilot study in Benin City is conducted, using a randomly selected sample of 10 persons (Leedy, 1985). A contract agent administered the questionnaire to the 10 respondents-and employed the same case study procedure used for collecting responses for the main study questionnaire-and each person answers the questions independently.

After all the participants complete the questionnaire, they are asked to explain if they had any difficulty understanding the questions and what factors, if any, may have impaired their answers. The responses from this pilot group are positive. All of the respondents indicate they clearly understand the questions, and answered sincerely, according to their perceptions of the situation addressed in each survey question. These reliable responses by the participants in the pilot study confirm the reliability and validity of the questionnaire. The 10 pilot study participants are instructed not to, and did not, participate in the final study.

\subsection{Instrument completion processes}

The research assistants administering questionnaires are set up at polling stations in each of four locations in Benin City. These stations are not accessible to anyone who is not qualified to be surveyed for this case study. It also is arranged so that every participant who comes to the survey stations is surveyed only once. All of the participants are instructed to read the questions and then respond to each item according to their own "perceptions of societal corruption" in Nigeria and "trust levels" in Nigerian government leaders. Each participant is shielded from the rest of the respondents, so none of the participants know how others respond.

Eight research assistants are recruited, who are knowledgeable about research procedures and help to administer the questionnaires. Each administrator is instructed regarding the rules and protocol for the conducting of the survey. Research assistants are counseled on the gravity of performing their duties properly, and the effect this would have on the validity of the results. The need for everyone involved in the administration of these survey questionnaires to conduct themselves according to the guidelines is assured. 
The survey team mapped each area where the survey is planned to take place. A rehearsal of the survey procedure is conducted with the administrators, to confirm that each research assistant is knowledgeable of the process, before the final questionnaire application is begun.

An area is reserved and prepared at each of the four locations for this survey, and five participants are allowed into the area to answer the questionnaire, at any one time. The administrators explain the procedures and read the rights and condition for the conduct of the survey, to all five participants, at the same time. After this, each participant is handed a questionnaire. The administrator repeats the process with the next five respondents, and the process continues until all of the questionnaires that are allocated for that site are distributed, filled out and collected, as planned. The participants are advised to not discuss their responses with anyone for the next 12 hours, because of privacy and security concerns, as well as the protection of the participants' rights to freely answer the questions.

\subsection{Design and purpose of each survey question}

The survey questionnaire has 26 questions. To analyze the "perceptions of societal corruption" in Nigeria and "trust levels" in the government leaders of Nigeria fully, the researchers divide the 26 questions into the following three sections: 1) general; 2) perception; and 3) trust. All the questions are analyzed using descriptive (narrative) statistics; however, questions 16, 19, and 20 are also used in a nonparametric chi-square, goodness-of-fit test. Question 25 is used in the chi-square tests for independence.

This study uses a nonparametric descriptive method of analysis. The independent variables are "perceptions of societal corruption" in Nigeria and ages of the participants. The dependent variable is "trust levels" for government leaders.

\subsection{Results and discussion}

Two types of strategies are used to analyze the case study questionnaire data. First, the distribution of the responses for each question on the questionnaire is analyzed using a univariate descriptive scheme. Key selected responses to these questions are presented next.

\subsection{Which of the following issues do you talk about the most?}

\begin{tabular}{lcr}
\hline \multicolumn{3}{c}{ Table 1: Issues of concern at family meetings } \\
\hline Issues discussed & No. of respondents & Percent of respondents \\
\hline Societal corruption & 710 & 72.7 \\
Politics & 110 & 11.3 \\
Economy & 109 & 11.2 \\
Tribal issues & 47 & 4.8 \\
Total & 976 & 100.0 \\
\hline
\end{tabular}

In question 4 (Table 1), the researchers seek to understand the priorities of Nigerians' concerns, ranging from the economy to culture, and from politics to social concerns, like societal corruption. The data show the respondents are the most concerned about and often talk about societal corruption. About 710 (72.7\%) of the 976 respondents talk about societal corruption frequently, 110 (11.3\%) of the respondents discuss politics, and 109 (11.1\%) discuss the economy. Forty-seven (4.8\%) of the 976 respondents to this question discuss tribal issues frequently, when they meet with family members or friends.

3.02 Which one of the following issues do you perceive as the biggest obstacle to the efficient functioning of government in Nigeria?

Table 2: Biggest obstacles to efficient functioning of government in Nigeria

\begin{tabular}{lcc}
\hline Biggest obstacle to government & No. of respondents & Percent of respondents \\
\hline Politics & 145 & 14.5 \\
Economy & 156 & 15.6 \\
Tribal issues & 23 & 2.3 \\
Societal corruption & 676 & 67.6 \\
Total & 1000 & 100.0 \\
\hline
\end{tabular}

The responses to question 5 (Table 2) are used to explain the ratings of activities or issues perceived to be a hindrance to the function of government. The data show 145 (14.5\%) of the respondents consider politics the problem for government not functioning efficiently, and another 156 (15.6\%) of respondents state that the 
Nigerian economy is the cause. Twenty-three (2.3\%) claim tribal issues are the reason for corruption. On the whole, $676(67.6 \%)$ perceive societal corruption in the Nigeria as the biggest obstacle to the government's ability to serve the public.

3.03 What is your level of trust in Nigeria with respect to government officials in general not to be corrupt?

\begin{tabular}{lcc}
\hline \multicolumn{3}{c}{ Table 3: Trust levels for government officials and corruption in Nigeria } \\
\hline Trust for government officials & No. of respondents & Percent of respondents \\
\hline Do not trust & 594 & 59.4 \\
Trust a little & 237 & 23.7 \\
Somewhat & 121 & 12.1 \\
Trust a lot & 48 & 4.8 \\
Total & 1000 & 100.0 \\
\hline
\end{tabular}

The levels of trust (Table 3), of those in positions of leadership and power, determine much of the Nigerian government's relationship with the public. Government makes policies that are expected to be obeyed, as a matter of trust, between the government and the public. If the level of trust for government leaders is low, disrespect for laws or the policies can result in crime and other social and political disorders. The respondents suggest that the level of trust for government leaders, not to be corrupt in Nigeria, is low. A total of 594 (59.4\%) respondents did not trust government officials not to be corrupt, 237 (23.7\%) trust government officials just a little, and 121 (12.1\%) somewhat trust government officials, generally. Only 48 (4.8\%) of the respondents believe that government officials could be trusted and were not corrupt. The results indicated that the participants perceive societal corruption as high, and trust for government leaders as very low.

3.04 Which one of the following issues do you perceive as the biggest obstacle to the efficient functioning of government in Nigeria?

\begin{tabular}{lrr}
\hline \multicolumn{2}{c}{ Table 4: Biggest obstacles to efficient functioning of government in Nigeria } \\
\hline Biggest obstacle to government & Number of respondents & Percent of respondents \\
\hline Politics & 145 & 14.5 \\
Economy & 156 & 15.6 \\
Tribal issues & 23 & 2.3 \\
Societal corruption & 676 & 67.6 \\
Total & 1000 & 100.0 \\
\hline
\end{tabular}

The responses to this question (Table 4) are used to explain the ratings of activities or issues perceived to be a hindrance to the function of government. The data show that $145(14.5 \%)$ of the respondents consider politics the problem for government not functioning efficiently, and another $156(15.6 \%)$ respondent's state that the Nigerian economy is the cause. Twenty-three (2.3\%) claim that tribal issues are the reason. On the whole, 676 $(67.6 \%)$ perceive corruption as the biggest obstacle to government's ability to serve the public.

3.05 Have you or one of your family members given a bribe to anyone in Nigeria in the past 5 years?

\begin{tabular}{lrr}
\hline \multicolumn{3}{l}{ Table 5: Respondents' immediate experience with bribery } \\
\hline Condition & No. of respondents & Percent of respondents \\
\hline Yes & 838 & 83.8 \\
No & 162 & 16.2 \\
Total & 1000 & 100.0 \\
\hline
\end{tabular}

This important question (Table 5) is a general test question about bribery, which is a prelude to the rest of the questions that emphasize corrupt activities that are the focus of this investigation. This question reports on how many people, in general, have participated in corrupt activities in Nigeria. Not unexpectedly, the data show that $838(83.8 \%)$ of the 1,000 respondents have knowledge and experience of societal corruption in Nigeria. Only 162 (16.2\%) may not have experienced corruption in Nigeria. One other issue is that some of the participants' family members may have had contact with corrupt people, but may not have discussed this with them before the survey.

In addition, when asked how likely the law is to be enforced regarding corruption; a majority of the respondents $(598,59.8 \%)$ believe that the laws will not be enforced, especially if the crime involves bribery and corruption of elected Nigerian leaders.

\subsection{Reasons for Nigeria's corrupt society}


Many Nigerians in positions of leadership engage in corrupt behavior because of their desire to stay in power, even if their actions damage the economy and infrastructure of the nation. Political incumbents want to remain in control of state institutions to prolong their economic plundering. This corrupt behavior favors the few, at the expense of the Nigerian public (Mbaku, 2000).

Nigeria has 350 separate languages, eleven official languages, and about 250 ethnic groups, which is part of the reason for tribal tension and alliances that support corrupt behaviors in the country (Falola, 1999). Kinship and tribal traditions are identified as reasons for the widespread societal corruption in Nigeria, and many other nations in Africa (Smith, 2001). Nigerians typically only trust their family members and those in their tribe, the so-called "circle of trust." Political leaders know this and establish mutual patron-client reciprocity, based on family-tribe associations. Political patronage is at the kin-tribe level, which are the social ties that perpetuate the Nigerian societal pattern of corruption.

Mbaku (2000) explains the role of the extended family in societal corruption, claiming that Africans, to be considered truly successful, are responsible not only for their immediate families, but are required to distribute monies obtained from their public office to members of their tribe. The mentality is, "he/she won the politicalpatronage lottery," and is now expected to share it with family and friends. It is for this reason that Nye (1967) claims that bureaucratic corruption was encouraged in the earlier years of Nigerian independence, beginning in 1960. A situation that allowed civil servants, with their small salaries, to help their extended families grow out of poverty and economic decline-through the use of corruption (Mbaku, 2000). As a result, corruption is now a tradition, firmly entrenched, sponsoring a culture of dependency that is now out of control.

An examination of the practice of corruption, in relation to kinship, is presented to help understand the social problems in Nigeria. Nafziger (1969) states the extended family system, or kinship, creates a situation that obligates near and distant relatives to care for one another, notwithstanding the source or extent of current income. When the income is not enough to meet the needs-at the time of a request from extended family members-those who have access to power may become involved in societal corruption, in an effort to meet the needs of their kinship.

Many families in Nigeria, and in other African countries, see the appointment of relatives to government positions as an opportunity to be corrupt, and to make the entire family wealthy (Guest, 2004; Nafziger, 1969). The Nigerian culture of dependency plays a role in the widespread corruption that plagues the country and other parts of Africa. Liebenow (1986) states that the economic success of the extended family is often dependent on the wealth of a single family member, who is expected to share money, food and hosing with his or her extended family, rather than accumulate individual wealth.

The strong extended family bond among Nigerians could be one reason that motivates government officials to take bribes and to be corrupt, in order to share the proceeds with their extended family members. In addition, many people in Nigeria feel that government money is no one's money in particular, so they steal it without moral misgivings or fear of being caught or prosecuted.

Societal corruption in Nigeria is often a family affair, in that one corrupt family will bring their kinsmen into office, and the family members will support and protect one another. Guest (2004) states that Nigerian politicians, once in power, strive to place as many people form their own family and tribe on the public payroll, as possible. Family and tribe allegiances are paramount, much stronger than state or national loyalties. Nigeria, which is comprised of many tribes, is vulnerable to having this weak sense of nation, which makes its citizens feel that government property needs to be shared with their kin. This is one reason for the difficulty in prosecuting societal corruption related cases in Nigeria.

The strong identity that most Africans have with their tribes sometimes supersedes the interests of the nation (Guest, 2004). The result often is that government officials take from the government without regard for the law. If there is any suspicion of financial mismanagement on the part of elected officials, the person at the head who shares with subordinates, could obstruct justice (French, 2004; Guest 2004). This tribal protection helps to minimize or eliminate the threat from outside groups, and it makes societal corruption investigations difficult and prosecution nearly impossible in Nigeria (French, 2004; Guest 2004; Nafziger, 1969). Whenever government corruption is widespread, the state is hampered in its ability to develop and maintain competent civil service professionals, who are vital to the country's success (Mbaku, 2000).

\subsection{How corruption is perpetuated in Nigeria}


One reason for the widespread societal corruption in Nigeria is the difficult economic situation facing most Nigerian workers, who are not paid for months, even though they have responsibilities. Situations like these could force people who never intended to commit crimes, to break the law, in order to survive. Falola and Ihonvbere (1985) suggest that the widespread societal corruption in Nigeria may be linked to government activities that have forced workers to ignore the law. People, who work, either for the government or for private organizations, are doing so to provide their family's needs. If their salaries are not paid, as happens very frequently in Nigeria, it remains difficult for them to respect the law.

Ostentation is another factor in the Nigerian way of life. People want to show off, by spending a great deal of money on social activities - in an effort to gain respect in their communities. Falola and Ihonvbere (1985) document an incident where loans for farm projects are used for activities that had nothing to do with agriculture. The corrupt officials use the stolen government money on themselves-purchasing luxury cars, building large new houses, and marrying and throwing lavish wedding parties. This is another example of the difficulty in stopping societal corruption.

Gutman (1976) claims that families control socialization, where viewpoints pass from generation to generation. This concept may explain why Nigerians emphasize extended family dependency and cohesiveness, rather than individual riches. It could be possible that socialization ideology, if used properly to educate families, could be the key to stopping corruption in Nigeria. Family socialization could help to explain the concept that respect among Nigerians is possible for any person who is not rich financially, but is honorable, because of his or her achievement in other areas in the community.

\subsection{Chi-Square statistics}

To answer research questions 1, 2 and 3, survey answers to questions 16, 19 and 20 are used in the analysis. A chi-square goodness-of-fit test is used to measure whether the observed nominal data fit the expected nominal data. Survey item 25 is used to answer research questions 4 and 5 , where a chi-square test for independence is used to analyze the answers. A level of significance of .05 is used as the basis for rejection of each question's null hypotheses.

3.8.1 Research question 1: In response to the question (survey question 16) regarding the level of societal corruption in Nigeria, does the distribution of the participants' responses differ from a hypothesized, non-skewed distribution?

Null hypothesis 1 is rejected, $\chi^{2}(3)=1020.70, p<.05$. Because the responses to how much societal corruption is perceived to exist in Nigeria is not distributed equally across all categories-this means that those who respond to this question are not equally divided into each of the response options in the question.

3.8.2 Research question 2: In response to the question (survey question 19) regarding the role of the president of Nigeria to bring about positive social change in the country, does the distribution of the participants' responses differ from a hypothesized, non-skewed equal distribution?

Null hypothesis 2 that the responses are distributed equally, across all categories is rejected, $\chi^{2}(3)=478.80, p<$ .05 . This means that the opinions of those who are surveyed concerning the level of perceived societal corruption and the level of confidence on the president, as an agent for positive social change, are not the same.

3.8.3 Research question 3: In response to the question (survey question 20) regarding the level of trust for Nigerian government officials in general and societal corruption in Nigeria, does the distribution of the participants' responses differ from a hypothesized, non-skewed equal distribution?

Null hypothesis 3 is rejected, $\chi^{2}(3)=703.80, p<.05$. Because the responses to the question (survey question 20) regarding the level of trust among Benin City residents in Nigeria, with respect to government officials and corruption, are not distributed equally across all categories- this test is for distributional adequacy to understand how well the statistical model reflects the data, between the observed and expected under the builtin model. This means that the more different the people are, the more different their perceptions of those people in positions of power will be regarding corruption.

3.8.4 Research question 4: What is the relationship between gender (survey question 3) and the belief that increased trust for government leaders will reduce societal corruption in Nigeria (survey question 25)? 
Null hypothesis 4 is rejected, $\chi^{2}(2)=53.72, p<.05$. The data indicate that gender is correlated to level of belief that increased trust in government reduces corruption in Nigeria. The chi-square statistical result means that the female participants are more likely than the male participants to report not believing that increased trust will reduce societal corruption in Nigeria.

3.8.5 Research question 5: What is the relationship between age (survey question 1) and the belief that increased trust in government will reduce societal corruption in Nigeria (survey question 25)?

Null hypothesis 5 is rejected, $\chi^{2}(6)=86.55, p<.05$. The data indicate that the ages of the participants are correlated to the level of belief that increased trust in government will help reduce societal corruption in Nigeria. The chi-square statistical result means that the older participants are more likely than the younger participants to report not believing that increased trust will reduce societal corruption in Nigeria.

\subsection{Explanation of research question results using Bandura's theory}

Societal corruption in Nigeria is connected to behavioral expectations, and to trends in economic conditions and social customs. Investigation of the questionnaire answers, given by the people of Benin City, Nigeria-about "perceptions of societal corruption" in Nigeria and "trust levels" in their national government leaders-is based upon an understanding of behavioral patterns, which is an appropriate method to evaluate Bandura's (1973) assertion that applying positive modeling influences-which entails using people with non-corruption positive behavioral traits as models-can reduce destructive behaviors and transmit better relationships in society. Bandura maintains that as long as people do not learn otherwise, they will persist in negative behaviors when confronting "situational demands." Bandura states that aggressive behaviors can be reduced at a personal level, implying that individual abilities vary and that the individual can strive to reduce aggression in different ways. Societal corruption is an aggressive behavior that needs to be evaluated and modeled, in order to find ways to eliminate it in Nigeria.

There are many methods used to correct behavior. While some of these approaches are good enough to modify the unwanted behavior, at other times, the methods may not yield optimal results. Bandura distinguishes between a fully changed behavior and a partial one. A partial change in behavior may be maintained more out of the lack of alternatives, than outright preference.

Bandura judges that the best behavioral modification for curbing negative behavior is one that is continually modeled - that is, by using the mediational processes of "attention, retention, reproduction and motivation" - to produce alternative positive constructive behavoiral models for adoption by corrupt government officials and business leaders. A particular problem in the community may be changed by using a group of people who are recruited and trained to incorporate positive behavioral characteristics, and once embraced by those with negative behavioral traits, is expected to achive behavioral modification objectives. When constructive behavioral alternatives are effectively identified and modeled, acceptance of favorable behavoiral qualities is increasingly possible.

\subsection{Conclusions and policy implications}

Leaders in Nigeria are only as ethical as the code-of-conduct prevalent in their country-where cultural, economic and legal factors contribute to the nation's corrupt society. Law enforcement and moral restrictions have broken down in Nigeria, leading to corrupt government officials and widespread poverty in the country.

Unless the problem of societal corruption in Nigeria is solved, Nigeria may become a failed state. According to Jordan (1999), Machiavelli's study of the decay and fall of the Roman Empire concluded that it was caused by wealth inequality, resulting in widespread poverty, which in turn, reinforced rampant political graft and corruption-producing a circular cause-and-effect downward spiral. Eventually, corrupt Roman leaders encouraged lawlessness in the nation. Causing law-abiding, but powerless Roman citizens, to lose trust in their government's leadership and leave the country, thereby abandoning Rome to her fate.

In Nigeria, since independence in 1960, vast wealth inequality exists, alongside uncontrolled political and business corruption. The recommendation of this research is to eradicate the criminal behavior that feeds off societal corruption, and is dangerous to Nigeria's survival as a state.

To change the culture of corruption in Nigeria, education is necessary, to instruct elected officials, civil servants, business leaders and Nigerian society, at large, on the importance of ethics and trust in business and government. This should take place within religious teachings at churches, mosques, temples and synagogues; and as part of 
moral philosophy courses offered at high schools. Colleges should be instituted to instruct political leaders, civil servants and business leaders in ethical behavior, as well as correct government procedures.

Political and business leaders in Nigeria should institute an ethics policy and implement the following five suggested reforms - which will help establish government leader's ethical integrity and improve citizens' trust and confidence in the Nigerian government, by:1) establishing a College of Public Services and Administration, with the responsibility of educating political and business leaders, and certifying quality disciplined civil servants who will focus on eradicating societal corruption in Nigeria; 2) enforce prosecutorial independence, headed by the Nigerian attorney general. This will increase judicial independence from politicians in the country; 3 ) reduce the chain-of-command in the Nigerian police force, to make the police more accountable to the people; 4) rescind constitutional immunity from prosecution for all sitting governors, when corruption issues are a concern; and 5) give all Nigerian citizens, including the news media, the freedom to express themselves, without fear or favor.

The citizens of Nigeria are responsible to change the destiny of Nigeria, and this research is a beginning for the many projects that will make this a reality. This study measures societal corruption, as perceived by a sample of residents from Benin City, Nigeria, along with levels of trust in their government leaders. The results indicate that "perceptions of societal corruption" in Nigeria are high and "trust levels" for government leaders are very low. Accordingly, recommendations are made for bringing positive social change to Nigeria. The database developed from this case study helps to better understand government and business corruption in Nigeria, and contributes to the literature as part of the continued priority to find solutions to Nigeria's societal corruption, and for other countries in Africa facing a similar situation.

Recommendations for future research include investigating corrupt family traditions of many Nigerians that have continued since independence in 1960, and contribute to societal corruption. The ways in which the country is able to withstand this criminal behavior should be studied. The success or failure of these societal eradication strategies need to be investigated and reevaluated to perfect a plan that will limit or remove societal corruption in Nigeria. As the theoritical framwork for this study suggests, if behavioral alternatives are effectively identified and modeled, then choosing an alternative constructive behavoir is increasingly possible.

\section{References}

Adjibolosoo, S. (2005). Economic underdevelopment in Africa: The validity of the corruption argument. Review of Human Factor Studies, 11(1), 90-112.

Afrobarometer. (2005). Nigerian survey questionnaire. Retrieved February 12, 2008, from http://www.afrobarometer.org/data.html

Agba, M. S. (2010). Combating corruption for sustainable development growth in Nigeria: Exploring the paradigm of divine option, International Business and management 1(1), 16-21.

Ayittey, G. B. (1992). Africa betrayed. New York: St. Martin's Press.

Bandura, A. (1973). Aggression: A social learning analysis. Englewood Cliffs, NJ: Prentice Hall.

Chughtai, A., Byrne, M., Flood, B. (2015). Linking ethical leadership to employee well-being: The role of trust in supervisor. Journal of Business Ethics, 128(3), 653-663. http://dx.doi.org/10.1007/s10551-014-2126-7

Daloz, J. (2005). Nigeria: Trust your patron, not the institutions. Comparative Sociology, 4(1-2), 155-172. http://dx.doi.org/10.1163/1569133054621969

Delhey, J., Newton, K. (2003). Who trusts: The origins of social trust in seven societies. European Societies, 5(2), 93-137. http://dx.doi.org/10.1080/1461669032000072256

Falola, T. (1999). The history of Nigeria: The Greenwood histories of the modern nations. Westport, CT: Greenwood Press.

Falola, T., Ihonvbere, J. (1985). The rise and fall of Nigeria's second republic, 1979-1984. Metuchen, NJ: Zed Books.

Ferguson, C. J. (2010). Genetic contributions to antisocial personality and behavior: A meta-analytic review from an evolutionary perspective. The Journal of Social Psychology, 150(2), 160-80. http://dx.doi.org/10.1080/00224540903366503

French, H. W. (2004). A continent for the taking: The tragedy and hope of Africa. New York, NY: Vintage Books.

Games, D. (2004). An oil giant reforms: The experience of South African companies doing business in Nigeria. Retrieved March 3, 20088, from http://www.polity. org.za/

Guest, R. (2004). The shackled continent: Power, corruption, and African lives. Washington, DC: Smithsonian Books.

Gutman, H. G. (1976). The Black family in slavery and freedom, 1750-1925. New York: Pantheon Books.

Igoni S.E., (2009). Perceptions of societal corruption and levels of trust in government: A case study of Benin City, Nigeria. PhD thesis. Walden University, College of Social and Behavioral Sciences. 
Ijomah, B. I. (2000). Nigeria's transition from military to civilian rule: An overview. Journal of Political and Military Sociology, 28, 293-310.

Jerome, A., Adjibolosoo, S., Busari, D. (2005). Addressing oil relate corruption in Africa. Is the push for transparency enough? [Special issue]. Review of Human Factor Studies, 11(1), 7-32.

Jordan, D. C. (1999). Drug politics: Dirty money and democracies. Norman, OK: University of Oklahoma Press.

Kulshreshtha, P. (2015). Ethical leadership and contemporary organizational ethics: Principles and cases. Journal of Leadership, Accountability and Ethics, 12(1), 94-97.

Leedy, P. (1985). Practical research: planning and design (3rd ed.). New York: Macmillan

Liebenow, J. G. (1986). African politics: Crises and challenges. Bloomington, IN: Indiana University Press.

Lussier, R. N. (2010). Human relations in organizations: Applications and skill building (8th ed.). Boston, MA: McGraw Hill.

Matsheza, P. (2007). Corruption: Concepts and definition, United Nations Office on Drugs and Crime. Retrieved from www.igac.net/ pdf/training presentations

Maxwell, A. E. (1961). Analysis qualitative data. London: Methuen.

Maxwell, J. (2005). Qualitative research design: An interactive approach. London: Sage.

Mbaku, J. M. (2000). Bureaucratic and political corruption in Africa: The public choice perspective. Malabar, FL: Krieger.

Nafziger, E. W. (1969). The effect of the Nigerian extended family on entrepreneurial activity. Economic Development and Cultural Change, 18(1), 26-33. http://dx.doi.org/10.1086/450400

Newman, A., Kiazad, K., Miao, Q., Cooper, B. (2014). Examining the cognitive and affective trust-based mechanisms underlying the relationship between ethical leadership and organisational citizenship: A case of the head leading the heart? Journal of Business Ethics, 123(1), 113-123. http://dx.doi.org/10.1007/s10551-0131803-2

Nye, J. (1967). Corruption and political development: A cost-benefit analysis. American Political Science Review, 61(2), 417-427. http://dx.doi.org/10.2307/1953254

Prentis, E. L., (1987). Operations management taxonomy. Journal of Operations Management, 7(1): 63-78. http://dx.doi.org/10.1016/0272-6963(87)90007-6

Sharif, M. M., Scandura, T. A. (2014). Do perceptions of ethical conduct matter during organizational change? ethical leadership and employee involvement. Journal of Business Ethics, 124(2), 185-196. http://dx.doi.org/10.1007/s10551-013-1869-x

Simon C.H. Chan, Wai-ming Mak. (2014). The impact of servant leadership and subordinates' organizational tenure on trust in leader and attitudes. Personnel Review, 43(2), 272-287. http://dx.doi.org/10.1108/PR08-2011-0125

Smith, D. J. (2001). Kinship and corruption in contemporary Nigeria. Journal of Anthropology, 66(3), 344-364. http://dx.doi.org/10.1080/00141840120095131

Werlin, H. H. (2003). Poor nations, rich nations: A theory of governance. Public Administration Review, 63, 329342. http://dx.doi.org/10.1111/1540-6210.00293

\section{APPENDIX: QUESTIONNAIRE}

1) What is your age bracket?

a) $25-30$ b) $31-35$ c) $36-40$ d) $41-u p$

2) How long have you lived in Benin City?

a) 0 to 5 years b) 6-10 years c) 11-15 years d) 16-up years

3) Which region of Benin City do you live?

a) North b) South c) East d) West

4) What is your gender?

a) Male b) Female

5) In general how would you describe the present economic condition of Nigeria?

a) Very good b) Fairly good c) Fairly bad d) Very bad

6) Have you or one of your family members given a bribe to anyone in Nigeria?

a) yes b) no

7) Please indicate whether each of the following aspects of our political /economical and social condition in Nigeria is worse or the same or better since 5 year ago?

A. Violent crime rate is a) Worse b) Much worse c) Better d) Much better

B. Poverty rate is a) Worse b) Much worse c) Better d) Much better

C. The gap between the poor and the rich is:

a) Worse b) Much worse c) Better d) Much better

8) To what extent do you think that the situations in question (7) has anything to do with fraud and embezzlement in government? 
a) Great deal b) No effect c) No opinion

9) How often do you listen to news about Nigeria?

a) Every day b) A few times a week c) A few times a month d) Once a month or less

10) When you get together with family or friends how often if at all do you discuss the social /political situation in Nigeria?

a) Never b) Occasionally c) Frequently

11) Which of the following issues do you talk about the most? (Do not answer this question if your answer is to question 11) is (a)

a) Societal corruption b) Politics c) Economy d) Tribal issues

12) Which one of the following issue do you perceive as the biggest obstacle to the efficient functioning of government in Nigeria?

a) Politics b) Economy c) Tribal issues d) Societal corruption

13) Please describe to what extent you agree with the following statement: As citizens, we should be more active in questioning the actions of our leaders:

a) Agree strongly b) Agree c) Disagree d) Not sure

14) In your opinion how democratic is Nigeria?

a) Fully democratic b) Democratic with some problems c) Not democratic d) Don't know

15) How satisfied are you with the level of democracy in Nigeria?

a) Very satisfied b) Somewhat satisfied c) Not satisfied at all d) No opinion

16) How much societal corruption if any do you perceive that exists in Nigeria?

a) A lot b) very little c) Not at all d) No opinion

17) To what extent do you believe that people talk about corruption in Nigeria?

a) Always b) a little c) Rarely d) I do not know

18) Please indicate below if any of the situations is better or worse now than it was few years ago?

A. Freedom to join political party of one's choice:

a) Much worse b) Somewhat worse c) Same d) Better

B. Freedom to vote for whom you want

a) Much worse b) Somewhat worse c) Same d) Better

C. Freedom of speech

a) Much worse b) Somewhat worse c) Same d) Better

D. Fair and equal treatment of all groups by the government

a) Much worse b) Somewhat worse c) Same d) Better

19) What role do you believe the president of Nigeria can play in abolishing societal corruption and bringing about positive social change?

a) Very important b) Important c) Not very important d) Not important at all

20) What is your level of trust in Nigeria with respect to government officials in general not to be corrupt?

a) Do not trust b) Trust a little c) Trust somewhat d) Trust a lot

21) In your opinion, what are the most important problems facing Nigeria that government should address? (Place in order of preference with 1 being the highest of importance

A. Unemployment a) 1 b) 2 c) 3 d) 4

B. Poverty $\quad$ a) 1 b) 2 c) 3 d) 4

C. Societal Corruption a) 1 b) 2 c) 3 d) 4

D. Crime a) 1 b) 2 c) 3 d) 4

22) In the following instances, how likely is the law to be enforced regarding corruption:

A. A top government official who receives a bribe:

a) Very likely b) Likely c) Not very likely d) Not at all likely

B. A person such as yourself receives a bribe:

a) Very likely b) Likely c) Not very likely d) Not at all likely

C. A relative of a top government official who receives a bribe:

a) Very likely b) Likely c) Not very likely d) Not at all likely

23) In general how much do you believe people in Nigeria to be corrupt?

a) Trust everyone b) Trust a few c) Trust no one d) No opinion

24) How much trust do you have for any one of the persons listed below regarding societal corruption?

A) Your relative:

a) Not at all b) Trust a little c) Trust somewhat d) Trust a lot

B) Your neighbor:

a) Not at all b) Trust a little c) Trust somewhat d) Trust a lot

C) Your Clans-people:

a) Not at all b) Trust a little c) Trust somewhat d) Trust a lot

D) Nigerians from other tribal groups: 
a) Not at all b) Trust a little c) Trust somewhat d) Trust a lot E) Foreigners who live in Nigeria:

a) Not at all b) Trust a little c) Trust somewhat d) Trust a lot

25) In general do you believe that people's increased trust for government will help reduce widespread societal corruption in Benin City in Nigeria?

a) Yes b) No c) No opinión

Please read this quote before answering this final question:

Quote Bandura (1973) stated that "even partially successful behavior is often maintained and valued, not because it is highly preferred, but because better alternatives are lacking" (p. 253).

26) Question: Would you agree, as implied by Bandura, that an alternative behavior in government can positively change trust level in government by Benin City residents and reduce societal corruption in Nigeria?

a) Yes b) No c) No opinión 